\title{
Mechanistic Investigation of Well-Defined Cobalt Catalyzed Formal E-Selective Hydrophosphination of Alkynes
}

DOI:

10.1021/acs.organomet.8b00281

\section{Document Version}

Accepted author manuscript

Link to publication record in Manchester Research Explorer

\section{Citation for published version (APA):}

Rajpurohit, J., Kumar, P., Shukla, P., Shanmugam, M., \& Shanmugam, M. (2018). Mechanistic Investigation of Well-Defined Cobalt Catalyzed Formal E-Selective Hydrophosphination of Alkynes. Organometallics, 37(14), 22972304. https://doi.org/10.1021/acs.organomet.8b00281

\section{Published in:}

Organometallics

\section{Citing this paper}

Please note that where the full-text provided on Manchester Research Explorer is the Author Accepted Manuscript or Proof version this may differ from the final Published version. If citing, it is advised that you check and use the publisher's definitive version.

\section{General rights}

Copyright and moral rights for the publications made accessible in the Research Explorer are retained by the authors and/or other copyright owners and it is a condition of accessing publications that users recognise and abide by the legal requirements associated with these rights.

\section{Takedown policy}

If you believe that this document breaches copyright please refer to the University of Manchester's Takedown Procedures [http://man.ac.uk/04Y6Bo] or contact uml.scholarlycommunications@manchester.ac.uk providing relevant details, so we can investigate your claim.

\section{OPEN ACCESS}




\section{Mechanistic investigation of well-defined cobalt}

\section{catalyzed formal $E$-selective hydrophosphination}

\section{of alkynes}

Jitendrasingh Rajpurohit, ${ }^{\perp}$ Pardeep Kumar, ${ }^{\perp}$ Pragya Shukla ${ }^{\perp}$, Muralidharan Shanmugam *\# and Maheswaran Shanmugam $* \perp$

${ }^{\perp}$ Department of Chemistry, Indian Institute of Technology Bombay, Powai, Mumbai-400076, Maharashtra, India.

\#Manchester Institute of Biotechnology (MIB), The University of Manchester, 131-Princess street, Manchester M1 7DN, UK.

KEYWORDS : Cobalt $\bullet$ Hydrophosphination $\bullet$ Electron paramagnetic resonance $\bullet$ Nuclear Magnetic Resonance.

Abstract: A formal $E$-selective hydrophophination of terminal and internal alkynes catalyzed by well-defined $\left[\mathrm{Co}\left(\mathrm{PMe}_{3}\right)_{4}\right]$ (A) complex is achieved under mild conditions in good-toexcellent yield. The reaction does not require any additives and/or external base for an efficient hydrophosphination reaction. The reaction provided excellent scope and good functional tolerance. Detailed spectroscopic analysis (NMR, EPR, and UV-Vis) revealed that the low valent cobalt( 0$)$ complex undergoes oxidative addition with diphenylphosphine followed by hydrometallation with alkyne and subsequent reductive elimination led to the expected product. The detailed spectroscopic analyses along with the isotopic labelled experiments facilitate to intercept the active intermediates that are involved in the catalytic cycle, which are detailed. It 
was revealed that the suprafacial (vide infra) delivery of $\mathrm{H}$ and phosphorus to $\pi$-alkynes in synfashion lead to formal $E$-vinyl phosphine.

\section{Introduction}

Addition of $\mathrm{X}-\mathrm{H}$ bond (where $\mathrm{X}$ is a heteroatom) to alkyne is of significant importance due to atom and step economy. ${ }^{1,2}$ This waste free method was widely employed for various hydrofunctionalization of unsaturated system, especially C-C double and triple bonds. Among them, hydrophosphination holds an edge over the others, due to the importance of organophosphorus compounds in antibiotic \& anti-tumor activity, metal catalysis and organocatalysis as witnessed in recent times. ${ }^{3,4}$ Hydrophosphination reaction, although, can be promoted by acids, bases, radicals, ${ }^{5,6}$ high temperature and organometallic reagents, these reactions suffer drastically from lower selectivity, poor functional groups tolerance and uncontrolled reactivity. The pioneering works of Gleuck et al. and Pringle et al. showed that these problems could be resolved by employing a metal catalyst. ${ }^{7,8}$ The metal catalyst, often tend to provide better regio and stereo selective control compared to the uncontrollable radical initiated reaction. ${ }^{3 b}$ However, the sluggish progress in developing new metal catalyst is perhaps due to the resultant trivalent vinyl phosphine is an excellent coordinating ligand, which is likely to poison the catalyst. Hence, the catalyst development for hydrophosphination reaction of

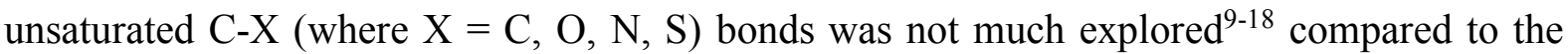
other hydro-functionalization reactions such as hydroboration, hydrosilylation and hydroamination, etc. ${ }^{16,19-40}$

Noble metals such as $[\mathrm{Pt}],[\mathrm{Pd}]$ and $[\mathrm{Ru}]$ based catalysts were predominantly employed to promote the hydrophosphination of unsaturated C-X (where $\mathrm{X}=\mathrm{C}, \mathrm{O}, \mathrm{S})$ bonds. ${ }^{41-43}$ Although conscious efforts were made by several research groups to develop cheap, environment friendly, less toxic metal catalyst (such as alkaline metal complexes), the reactions either require high catalyst loading or suffer from poor regio and stereo selectivity of the 
products. ${ }^{14,44-48}$ Transition metal catalyst developed for the hydrophosphination reaction, on the other hand, often requires other additives, in particular with the late transition metal catalyst. $^{12,49-52}$ For example, Oshima and co-workers elegantly demonstrated the use of inexpensive copper and $\left[\mathrm{Co}(\mathrm{acac})_{2}\right]$ catalyst for provoking hydrophosphination of alkynes but it requires additional strong base $\mathrm{Cs}_{2} \mathrm{CO}_{3}$ and a reactive $n$-BuLi respectively. ${ }^{53}$

Therefore, we sought to unveil a robust, cheap and abundant transition metal catalyst for hydrophosphination reaction. We, herein report an efficient, stereo-selective hydrophosphination of alkynes catalyzed by the well-defined cobalt catalyst $\left[\mathrm{Co}\left(\mathrm{PMe}_{3}\right)_{4}\right](\mathbf{A})$ and investigated the mechanism of the reaction to intercept the various intermediates involved in the catalytic cycle. Such mechanistic investigations are extremely scarce in the literature. In this process, we have identified various intermediates involved in the catalytic cycle with the aid of multi-spectroscopic analysis, and isotopic labelling experiments, which are described below.

\section{Results and Discussion}

This well-defined catalyst $\mathbf{A}$ yields formal $E$-selective hydrophosphination of terminal and internal alkynes exclusively under mild reaction conditions and the reaction proceeds smoothly via syn-addition of P-H bond to the alkyne without any additional bases or organometallic reagent (Scheme 1). We began our investigation by screening various reaction parameters using $0.9 \mathrm{mmol}$ of phenylacetylene and dipheylphosphine with $5 \mathrm{~mol} \%$ of $\mathbf{A}$. The catalytic reaction was optimized to isolate the product with better yield/stereo selectivity by screening solvent, temperature and catalyst loading. A better stereo selectivity $(E)$ was obtained in low polar solvent compared to the polar solvents presumably due to the sluggish isomerization process of the product in low polar solvent compared to the polar solvent. Such scenario witnessed in the literature, for example solvent polarity dependent stereo selective product obtained for hydrogenation of alkynes. ${ }^{54}$ 
Scheme 1. Cobalt catalyzed hydrophosphination of alkynes..

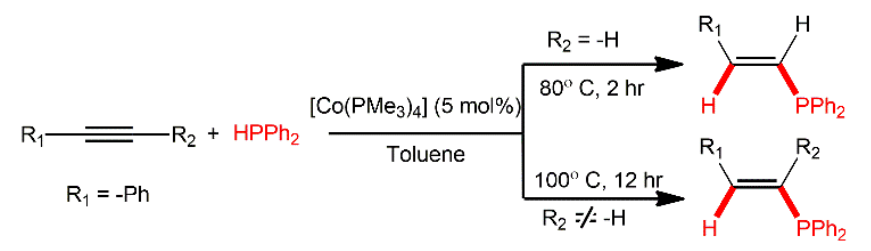

It is noticed that, high yield of the product obtained while using toluene as solvent with the catalyst loading of $5 \mathrm{~mol} \%$ at $80{ }^{\circ} \mathrm{C}$ for terminal alkyne $\left(100{ }^{\circ} \mathrm{C}\right.$ for internal alkyne; Scheme $1)$.

Scheme 2. Scope of the terminal alkynes. ${ }^{\text {a, b }}$
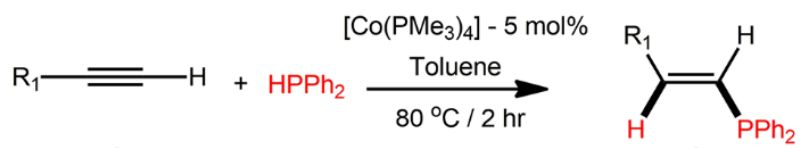

1

2
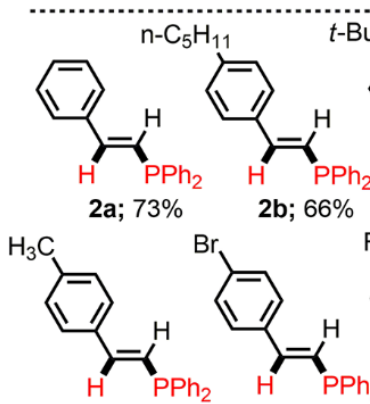

2b; $66 \%$

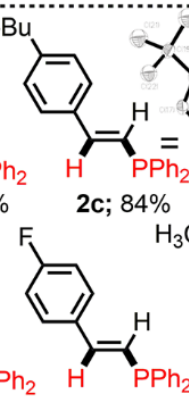

.......

2d; $71 \%$

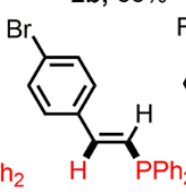

$\mathrm{H}_{3} \mathrm{CO}$
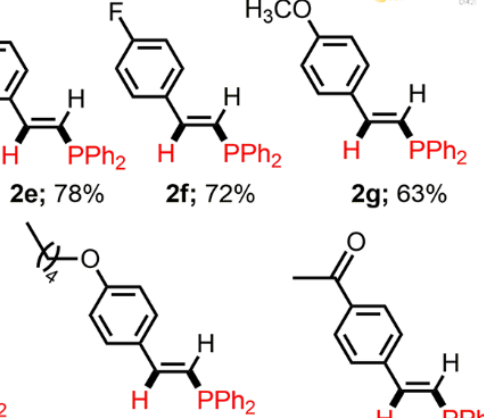

2g; $63 \%$
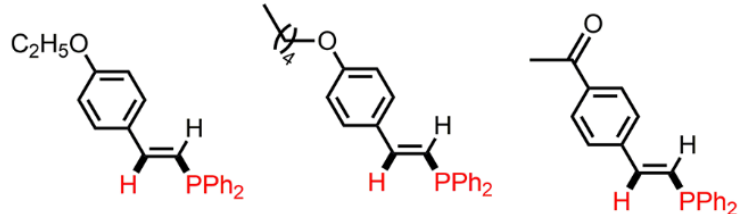

2h; $68 \%$
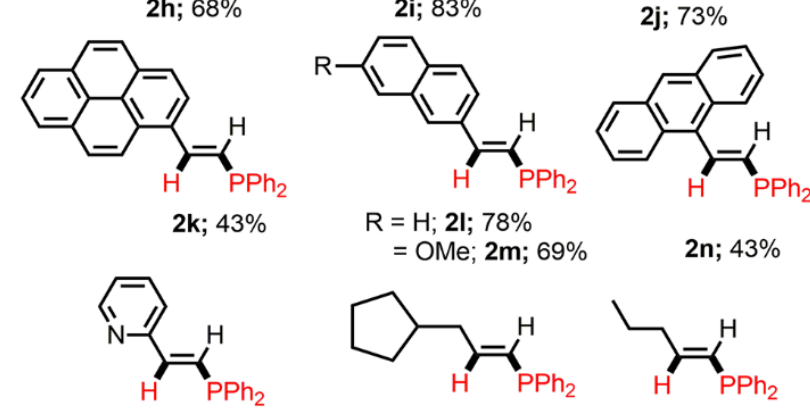

$\mathrm{R}=\mathrm{H} ; \mathbf{2 l} ; \mathbf{7 8 \%}$

= OMe; $2 \mathrm{~m} ; 69 \%$

2n; $43 \%$

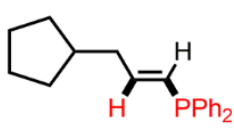

2p; $68 \%$

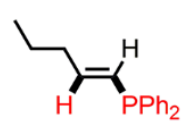

2q; $29 \%$

a All reactions were carried out under Argon atmosphere, unless otherwise stated, using 1/PPh2/[Co] in $0.9 / 0.9 / 0.045 \mathrm{mmol}$ at $80{ }^{\circ} \mathrm{C}$ in toluene $(3 \mathrm{~mL}) .{ }^{b}$ Isolated yield after sulfidation. 
We observed neither dimerization of alkyne nor poisoning of catalyst by the product, which is an added advantage for the efficient product formation. Slightly higher temperature is required as the catalyst is latent and liberation of $\mathrm{PMe}_{3}$ (from $\mathbf{A}$ ) is effective at higher temperature to access to active catalyst precursor (vide infra). Careful analysis of the product indicate that the phosphine and $\mathrm{H}$ are added on the same side of the alkyne, which led to formal $E$-vinyl phosphine (See also tables S1-S4 of ESI).

With the best conditions in hand, we next examined the scope of terminal alkynes (Scheme 2). Electron donating group such as $\mathrm{Me}, \mathrm{n}$-pentyl and $t$-Bu substituent at the $p$-position provided good yield with excellent stereo- and regio-selectivity. Further, the crystal structure of 2c unequivocally supports the $E$-selective product formation (Figure S1, Table S5), where the phosphine and phenyl rings are trans to each other. The electronic effect of the substituent (i.e. either electron withdrawing or electron donating groups) on the phenyl ring does not appear to have influence on the progress of the catalytic reaction and hence the yield of product. For example, electron withdrawing groups such as $-\mathrm{Br},-\mathrm{F}$ and acetyl-groups as well as electron releasing groups (such as $-\mathrm{OMe},-\mathrm{OEt}, \mathrm{OC}_{5} \mathrm{H}_{11}$ ) were well tolerated and provide excellent product yield without much variation in yield $(\mathbf{2 e - 2 j})$. The reaction can be further extended to hydrophosphination of fused aromatic ring such as napthyl, anthracyl and pyrenyl substituted acetylene in good yield (2k-2n). To our delight, even heterocycles can be tolerated albeit in moderate yield (2o). Additionally, the reactivity of aliphatic alkynes, namely tetrahydrocyclopentyl propynyl acetylene and 1-pentyne are tested. The expected hydrophosphinated product was isolated in moderate yield (2p-q), but formation of small amount of other regio-isomer $\left(E^{\prime}\right)$ is witnessed with the ratio of $E: E^{\prime}$ ratio $=3: 1$, see table S6 of ESI). We would like to emphasize that certain transition metal catalyst does not promote hydrophosphination reaction of aliphatic alkyne, ${ }^{12,13}$ those which facilitate smooth progress of 
the reaction often lost its regio-selectivity, a common, yet challenging problem known in the literature. ${ }^{18,55}$

Although hydrophosphination of terminal alkynes reported in the past but their corresponding extension to the internal alkynes often failed to provide the vinyl phosphine or it did not provide any control over stereo-selectivity due to the vinilydene pathway. ${ }^{10}$ Under the optimized experimental conditions (Scheme 1), we further extent the scope of the internal alkynes (Scheme 3). Bi-aryl acetylene gave moderate isolated yield of the expected product but the product yield is significantly improved $(93 \% ; 3 \mathbf{c})$ when 1-phenylpropyne is used with one single regio-isomer. The regio and stereo selectivity is absolutely preserved in 3a-c, while in case of electronically biased alkynes $\mathbf{3 d}$ and $\mathbf{3 e}$, the regio-selectivity is compromised (E:E' ratio for $\mathbf{3 d}(55: 45)$ and $\mathbf{3 e}(69: 31)$, see Table S6 of ESI) to some extent. It is witnessed, hitherto, from the literature that promoting hydrophosphination reaction of internal alkynes with hetero-aromatic ring substituent (or electronically biased substrate) is a challenging task. In majority of the cases, reaction does not proceed due to the catalyst poisoning, while in viceversa scenario, controlling stereo-and regio selectivity of the reaction is a demanding task and an uphill process. The analyses of product $(\mathbf{3 c} \& \mathbf{3 e})$ revealed that the phosphorous atom prefers to add sterically less hindered carbon site of an alkyne.

Intrigued by this reactivity and stereo-selectivity, we have turned our attention to predict the nature of intermediate formed to better understand the mechanism of reaction. We first carried out deuterium labelling experiments using $\mathrm{PPh}_{2} \mathrm{D}$ (78\% deuterium enriched) with 4-tbutylphenylacetylene to understand the origin of $E$-selective product formation. Careful analysis of ${ }^{1} \mathrm{H}$ and ${ }^{2} \mathrm{H}-\mathrm{NMR}$ revealed that the intensity of doublet of doublet observed at 7.58 ppm drastically reduced in ${ }^{1} \mathrm{H}$ NMR with the concomitant appearance of ${ }^{2} \mathrm{H}$ signal in ${ }^{2} \mathrm{H}$ NMR at the same ppm implies that deuterium atom (of the $\mathrm{PPh}_{2} \mathrm{D}$ ) bound to the internal carbon of the alkyne (Figure S2 of ESI). The coupling constant observed in ${ }^{1} \mathrm{H}$ NMR signal (observed at 
$\left.\left.6.91 \mathrm{ppm}(\mathrm{dd}){ }^{3} J_{\mathrm{H}-\mathrm{H}}=16.3 \mathrm{~Hz},{ }^{3} J_{\mathrm{P}-\mathrm{H}}=21 \mathrm{~Hz}\right)\right)$ and the peak observed at $-11.2 \mathrm{ppm}$ in ${ }^{31} \mathrm{P} \mathrm{NMR}$ of the product confirms the $s y n$-addition results in $E$-selective product formation.

Scheme 3. Scope of the internal alkynes. ${ }^{\mathrm{a}}$.

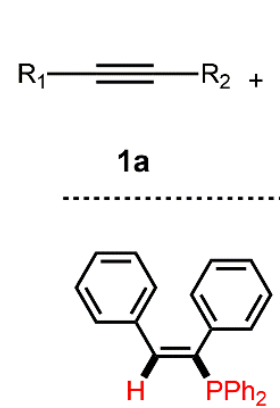

3a; $48 \%$

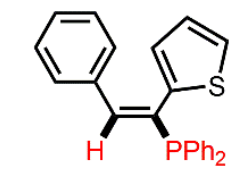

3d; $48 \%$
$\left[\mathrm{Co}\left(\mathrm{PMe}_{3}\right)_{4}\right]-5 \mathrm{~mol} \%$

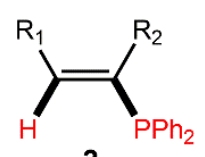

3

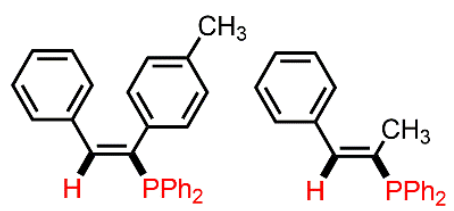

3b; $47 \% \quad$ 3c; $93 \%$

${ }^{\text {a }}$ All reactions were carried under the same conditions as scheme 2 at $100{ }^{\circ} \mathrm{C}$.

We next examined the reaction by following stoichiometric experiment between $\mathbf{A}$ and $\mathrm{PPh}_{2} \mathrm{H}$ through various spectroscopic techniques. Prior to the experiment, we have characterized the catalyst $\mathbf{A}$ through ${ }^{1} \mathrm{H}$ and ${ }^{31} \mathrm{P}$ NMR spectra in $\mathrm{C}_{6} \mathrm{D}_{6}$ at room temperature. The characteristic peak for methyl protons and ${ }^{31} \mathrm{P}$ signal observed at 1.26 and $-0.14 \mathrm{ppm}$ respectively. This indicates that all the four $-\mathrm{PMe}_{3}$ groups bound to the cobalt ion are chemically equivalent (Figure S3 of ESI).

Equimolar amount of the $\mathbf{A}$ and $\mathrm{PPh}_{2} \mathrm{H}$ were mixed and the reaction was monitored by ${ }^{1} \mathrm{H}$ NMR spectrum. A broad signal observed at $0.89 \mathrm{ppm}$ is attributed to a metal free $-\mathrm{PMe}_{3}$ group in solution, which is likely due to ligand $\left(\mathrm{PMe}_{3}\right)$ dissociation from $\mathbf{A}$ followed by $\sigma$ coordination of $\mathrm{PPh}_{2} \mathrm{H}$. This free $\mathrm{PMe}_{3}$ group ${ }^{31} \mathrm{P}$ signal was noted at $-62.5 \mathrm{ppm}$ (see green trace in Figure 1; assignment of this signal was based on ${ }^{1} \mathrm{H}$ and ${ }^{31} \mathrm{P}$ NMR recorded in $\mathrm{C}_{6} \mathrm{D}_{6}$ for commercially available $1 \mathrm{M}$ solution of $\mathrm{PMe}_{3}$; Figure S4). This further undergoes heterolytic cleavage via $2 \mathrm{c}-3 \mathrm{e}^{-}$transition state to provide a penta coordinated $\left[\mathrm{Co}{ }^{\mathrm{II}}(\mathrm{H})\left(\mathrm{PPh}_{2}\right)\left(\mathrm{PMe}_{3}\right)_{3}\right]$ 
oxidative addition product $\mathbf{B}$, which is also consistent with EPR, UV-Vis spectroscopy (vide infra).

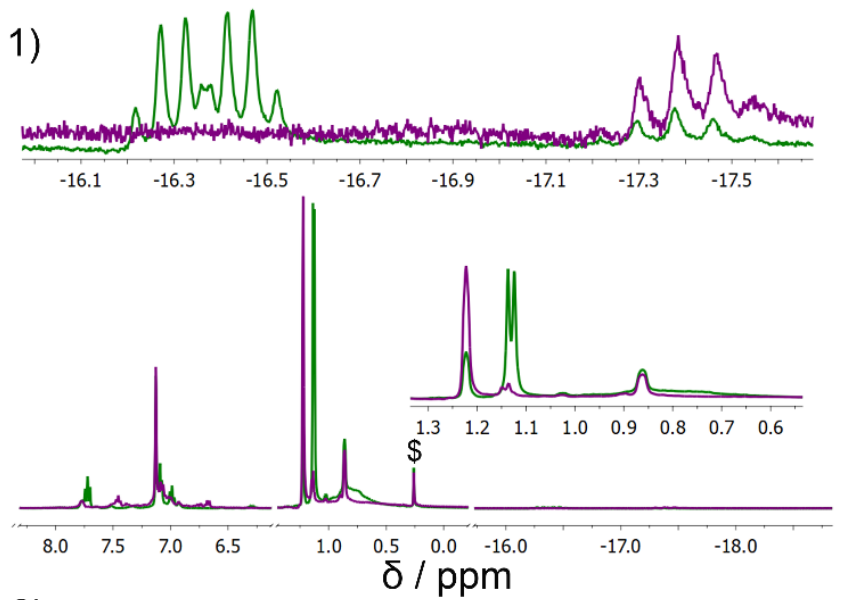

2)

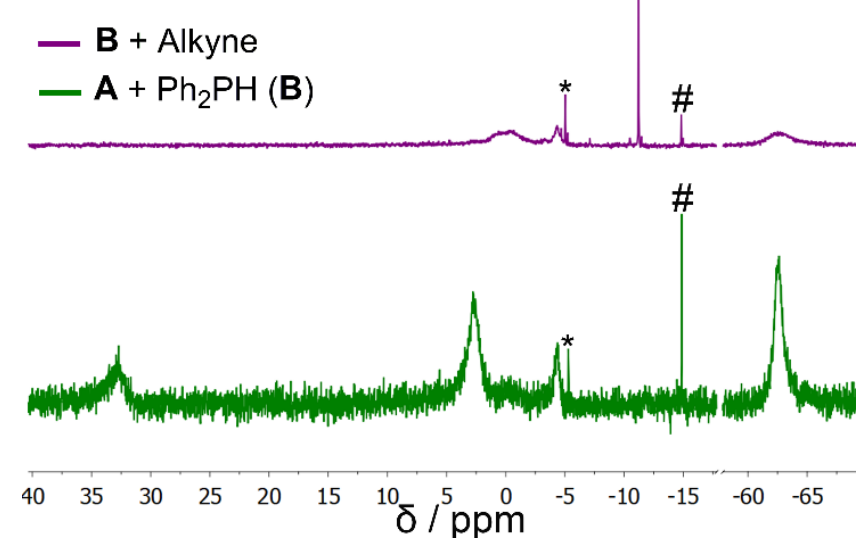

Figure 1. ${ }^{1} \mathrm{H}$ NMR (panel 1) and ${ }^{31} \mathrm{P}$ NMR (Panel 2) of $\left[\mathrm{Co}\left(\mathrm{PMe}_{3}\right)_{4}\right]$ treated with $\mathrm{PPh}_{2} \mathrm{H}$ (green trace) in $\mathrm{C}_{6} \mathrm{D}_{6}$. The magenta trace corresponds to substrate added into the $\left[\mathrm{Co}\left(\mathrm{PMe}_{3}\right)_{4}\right]+\mathrm{HPPh}_{2}$ reaction mixture. In both cases, the spectra recorded in $400 \mathrm{MHz} N M R$ instrument using $\mathrm{C}_{6} \mathrm{D}_{6}$ as solvent. Panel 1 inset: The magnified region of ${ }^{1} \mathrm{H}$ NMR spectra observed between -16 to -

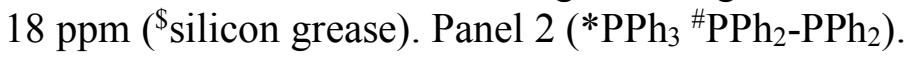

Formation of $\mathbf{B}$ was confirmed further by ${ }^{1} \mathrm{H}$ NMR where the methyl protons of - $\mathrm{PMe}_{3}$ groups (coupled with phosphorous of $\mathrm{PPh}_{2}$ group) observed at $1.16 \mathrm{ppm}$ as a doublet and the aromatic protons of the $-\mathrm{PPh}_{2}$ group as multiplets between 6.8 to $7.8 \mathrm{ppm}$ which are coordinated to the $\mathrm{Co}(\mathrm{II})$ ion in $\mathbf{B}$ (Figure 1; also see inset of panel 1)). Its corresponding ${ }^{31} \mathrm{P}$ signals are observed at $2.68\left(-\mathrm{PMe}_{3}\right)$ and $32.5\left(-\mathrm{PPh}_{2}\right) \mathrm{ppm}$ (green trace in Figure 1 (panel 2)). The weak ${ }^{1} \mathrm{H}$ NMR signal observed in -16.1 (doublet of quartet) to $-17.6 \mathrm{ppm}$ (quintet) is ascribed to the hydride 
ion bound to the Co(II) ion (intermediate $\mathbf{B} \& \mathbf{C}$ (vide infra)), which is consistent with the chemical shift value reported in the literature for a $\mathrm{Rh}-\mathrm{H}$ complex. ${ }^{56}$ Due to highly reactive nature of $\mathbf{B}, \mathbf{B}$ presumably reacts with another equivalent of $\mathrm{HPPh}_{2}$ (likely via sigma-bond metathesis), results in the formation of coupled product $\mathrm{PPh}_{2}-\mathrm{PPh}_{2}$ and $\left[\mathrm{Co}{ }^{\mathrm{II}}(\mathrm{H})_{2}\left(\mathrm{PMe}_{3}\right)_{4}\right](\mathbf{C}$, Figure 1, see also scheme 4) complex. The catalytic reaction was carefully monitored again through GC-MS analysis, which clearly reveals that neither $\mathrm{H}_{2}$ gas evolution nor hydrogenated products (such as alkenes and alkanes) observed in the presence of alkyne substrate (data not shown). This reveals that $\mathbf{C}$ is robust and does not undergo any further reaction, which is consistent with NMR observation that the peaks correspond to $\mathbf{C}$ (both ${ }^{1} \mathrm{H}$ and ${ }^{31} \mathrm{P}$ ) remain unchanged even after the addition of alkyne substrate (vide infra). The other alternative, reductive elimination pathway for the formation of coupled product $\left(\mathrm{PPh}_{2}-\mathrm{PPh}_{2}\right)$ from $\mathbf{B}$ is omitted, because this will results in $\mathrm{Co}(0)$ formation which is an EPR active species. However, experimentally, the products obtained upon addition of $\mathrm{PPh}_{2} \mathrm{H}$ with $\mathbf{A}$ found to be EPR silent (vide infra), implies that cobalt remains in +2 state. The quintet signature observed at -17.4 ppm for the hydride ion bound to Co(II) (see inset of Figure 1 (panel 1)) is due to the splitting of its ${ }^{1} \mathrm{H}$ NMR signal by four chemically equivalent $\mathrm{PMe}_{3}$ groups bound to $\mathrm{Co}(\mathrm{II})$ ion in $\mathbf{C}$. The ${ }^{1} \mathrm{H}$ NMR and ${ }^{31} \mathrm{P}$ NMR signals of $\mathrm{PMe}_{3}$ group coordinated with the $\mathrm{Co}(\mathrm{II})$ ion in species C observed at $1.25 \mathrm{ppm}$ and $-4.4 \mathrm{ppm}$ (Figure 1) respectively. The existence of both $\mathbf{B}$ and $\mathbf{C}$ species (in the stoichiometric reaction) further indirectly confirmed by the presence of ${ }^{31} \mathrm{P}$ signal at $-14.9 \mathrm{ppm}$, which attributed to the formation of $\mathrm{Ph}_{2} \mathrm{P}-\mathrm{PPh}_{2}$ coupled product. The observed chemical shift value of this coupled product is consistent with the literature reports. ${ }^{57}$ Not only in stoichiometric reaction, but also in the presence of excess $\mathrm{PPh}_{2} \mathrm{H}\left(\mathbf{A}: \mathrm{PPh}_{2} \mathrm{H}=1: 20\right.$ (as per in the catalytic reaction condition, but in the absence of alkyne substrate)), formation of small amount of $\mathrm{Ph}_{2} \mathrm{P}-\mathrm{PPh}_{2}(\sim 5 \%)$ was observed along with $\mathbf{B}$ confirmed through ${ }^{31} \mathrm{P}$ NMR (Figure S5 of ESI). Nevertheless, we would like to point out that, the coupled product $\left(\mathrm{Ph}_{2} \mathrm{P}-\right.$ 
$\mathrm{PPh}_{2}$ ) formation is prevented during the catalytic reaction, as confirmed through ${ }^{31} \mathrm{P} \mathrm{NMR}$, in the presence alkyne substrate (Figure S6 of ESI), reveals the highly reactive nature of $\mathbf{B}$.

To prove the origin of hydride in $\mathbf{B}$ and $\mathbf{C}$ from $\mathrm{PPh}_{2} \mathrm{H}$ upon oxidative addition, we have performed the stoichiometric reaction of deuterated diphenyl phosphine $\left(\mathrm{PPh}_{2} \mathrm{D}(60 \%\right.$ enriched)) with $\mathbf{A}$ in $\mathrm{C}_{6} \mathrm{H}_{6}$. The ${ }^{2} \mathrm{H}$ NMR spectrum of this benzene solution shows a peak at $16.3 \mathrm{ppm}$, which is exactly the same chemical shift value observed for the hydride bound to $\mathrm{Co}(\mathrm{II})$ ion in $\mathbf{B}$, in ${ }^{1} \mathrm{H}$ NMR (Figure S7 of ESI). On the other hand, we could not observe deuterium incorporation in species $\mathbf{C}$. The isotopic labelled experiments and detailed NMR analysis unambiguously proves that the oxidative addition is the initial step of the catalytic cycle.

Next, we added the alkyne to the in-situ generated species (B and $\mathbf{C}$ ), subsequent changes were monitored again through ${ }^{1} \mathrm{H}$ and ${ }^{31} \mathrm{P}$ NMR spectra (Figure 1, magenta trace). The ${ }^{31} \mathrm{P}$ signal (2.68 and $32.5 \mathrm{ppm})$ and ${ }^{1} \mathrm{H}$ NMR signal (-16.35 ppm) observed for species $\mathbf{B}$ is totally disappeared. Further, the intense doublet observed in ${ }^{1} \mathrm{H}$ NMR at $1.16 \mathrm{ppm}$ for $-\mathrm{PMe}_{3}$ group coordinated to $\mathrm{Co}(\mathrm{II})$ in $\mathbf{B}$, signal intensity drastically decreased. This entire scenario, firmly advocates that the alkyne insert between $\mathrm{Co}-\mathrm{H}$ followed by reductive elimination lead to styrenyldiphenylphosphine. A new intense ${ }^{31} \mathrm{P}$ NMR signal at $-11.2 \mathrm{ppm}$ is the characteristic signature of an $E$-selective styrenyldiphenylphosphine derivative, which is consistent with the other literature reports. ${ }^{18}$ The unchanged ${ }^{1} \mathrm{H}$ NMR signal intensity at $0.86 \mathrm{ppm}$ (which was attributed to the free $-\mathrm{PMe}_{3}$ originated from $\mathbf{A}$ upon oxidative addition) even after the reductive elimination, indicates that $\operatorname{Co}(0)$ regenerated after the reductive elimination is not same as $\mathbf{A}$. This regenerated $\operatorname{Co}(0)$ is referred as $\mathbf{A}^{\prime}$ hereafter. This designates that, a concurrent ligand dissociation and oxidative addition of $\mathrm{PPh}_{2} \mathrm{H}$ is the first step of catalytic cycle. Formation of A' further, strongly corroborated with UV-Vis and EPR measurements (vide infra). Further, $\mathbf{C}$ remains as the resting state and is not catalytically active under the reaction conditions. This 
fact indeed verified from the unchanged ${ }^{1} \mathrm{H}$ and ${ }^{31} \mathrm{P}$ signal even after the addition of alkyne substrate (see magenta trace in Figure 1).

To provide additional support for the oxidative addition of $\mathrm{PPh}_{2} \mathrm{H}$ with $\left[\mathrm{Co}\left(\mathrm{PMe}_{3}\right)_{4}\right](\mathbf{A})$, we have recorded UV-Visible spectrum for both $\mathbf{A}$ and in-situ generated products (stoichiometric amount of $\mathbf{A}$ and $\mathrm{PPh}_{2} \mathrm{H}$ ) in a sealed cuvette (Figure 2). The spectral features of both $\mathbf{A}$ and insitu generated complexes are distinctly different. For $\mathbf{A}$ there is no significant absorption feature, whereas for the in-situ generated product two distinct d-d transitions centered at 404 $\mathrm{nm}$ and $473 \mathrm{~nm}$ is observed, ${ }^{58,59}$ for intermediate species $\mathbf{B}$ and $\mathbf{C}$.

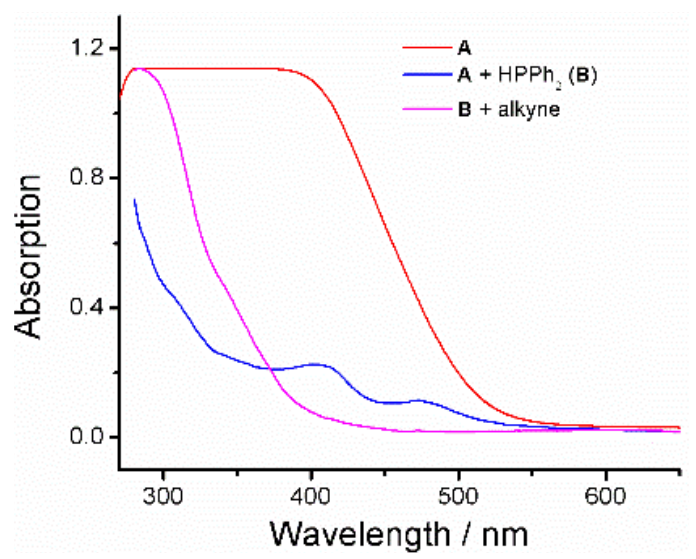

Figure 2. UV-Vis spectrum of $\mathbf{A}$ (red trace), in-situ generated intermediate $\mathbf{B}$ upon $\mathrm{PPh}_{2} \mathrm{H}$ addition to $\mathbf{A}$ (blue trace) and magenta trace represents the alkyne added to $\mathbf{B}$ measured in toluene $\left(2.8 \times 10^{-8} \mathrm{mmol}\right)$ at room temperature.

Upon addition of 4-bromophenylacetylene to the reaction mixture results in no absorption features as like A, with the synchronous disappearance of the absorption bands observed earlier. The UV-Vis spectrum upon addition of alkyne into the in-situ generated species, however, is not exactly resembles that of $\mathbf{A}$. This suggests that $\mathbf{A}$ is not a catalytically active species, but A' which is confirmed by its spin Hamiltonian parameters extracted from EPR measurement compared to $\mathbf{A}$ (vide infra)).

In order to shed light on the electronic structure of the various species involved in the hydrophosphination catalytic cycle low temperature, X-band EPR measurements were performed on $\mathbf{A}$ by dissolving in toluene, as a frozen toluene glass at $5 \mathrm{~K}$. The EPR spectrum 
of $\mathbf{A}$ measured at $5.0 \mathrm{~K}$ shows nicely resolved hyperfine fine structures due to the interaction of unpaired electron spin on cobalt with the nuclear spin of ${ }^{59} \mathrm{Co}\left(I\left({ }^{59} \mathrm{Co}\right)=7 / 2\right)$. The cobalt hyperfine couplings are clearly visible in the $g_{\text {II }}$ region, whereas it is severely overlapped and poorly resolved in the $g_{\perp}$ regions. Simulation of the experimental EPR spectrum of $\mathbf{A}$ gave principal values of the $g$-tensor and components of hyperfine coupling for ${ }^{59} \mathrm{Co}$ nucleus; $g=$ $[2.1626,2.1601,1.9832], A\left({ }^{59} \mathrm{Co}\right)=[13070179] \mathrm{MHz}$ with isotropic hyperfine coupling, of $a_{\text {iso }}\left({ }^{59} \mathrm{Co}\right)=126.3 \mathrm{MHz}\left(\right.$ see black trace in Figure 3) ${ }^{60}$ The Gaussian line width of $3.89 \mathrm{mT}$ was used to reproduce the experimental line shape. The observed EPR line shape and the extracted spin-Hamiltonian parameters are in good agreement with the previously reported $\operatorname{Co}(0)$ complexes with organophosphorous ligands in the coordination sphere with distorted tetrahedral geometry. ${ }^{61-65}$

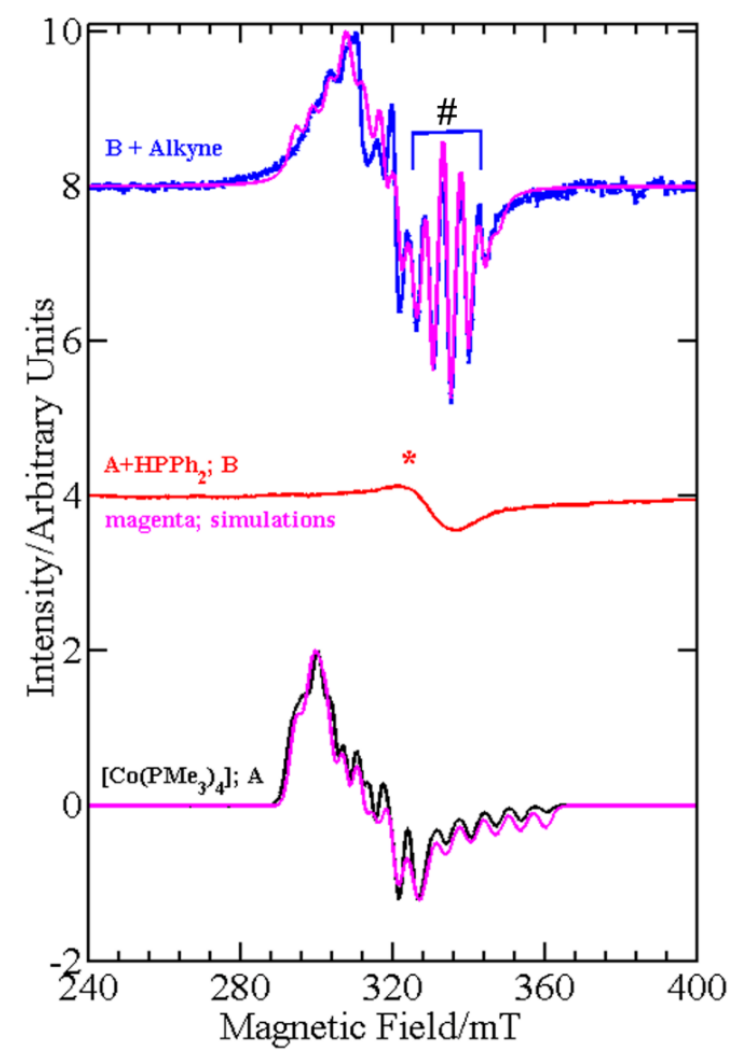

Figure 3. X-band CW-EPR spectra of $\left[\mathrm{Co}\left(\mathrm{PMe}_{3}\right)_{4}\right]$ (black trace; $\left.\mathbf{A}\right)$, in-situ generated products upon $\mathrm{PPh}_{2} \mathrm{H}$ addition to $\mathbf{A}$ (red trace; B). Alkyne treated with $\mathbf{B}$ (blue trace) measured at $5.0 \mathrm{~K}$ in toluene solution. The solid magenta traces represent the simulations of the experimental spectra using the parameters described in main text. ${ }^{*}$ denotes the signal from the resonator 
cavity. \# represents the EPR signals originate from a radical impurity $(<4 \%)$. See main text for details.

When diphenylphosphine $\left(\mathrm{HPPh}_{2}\right)$ is added into the solution of $\mathbf{A}$, the characteristic EPR features of $\mathbf{A}$ are completely disappeared (see red trace in Figure 3). Similar trend has been observed previously when $\mathrm{Co}(0)$ complex $\left.\left[\mathrm{Co}\left(\mathrm{C}_{2} \mathrm{H}_{7} \mathrm{O}_{2}\right)_{2}\right)^{-} \mathrm{Al}\left(\mathrm{c}_{2} \mathrm{H}_{5}\right)_{3}\right]$ was treated with dihydrogen gas. ${ }^{64}$ This implies that ligand exchange takes place (oxidative addition) at the expense of valence state of the cobalt centre in A. However, literature precedents are known for some reactions that there is no change in oxidation state of $\operatorname{Co}(0)$ upon ligand substitution. ${ }^{61,66-68}$ Oxidative addition leads to the formation of species $\mathbf{B}$ and $\mathbf{C}$, which are EPR silent, in contrast to $\mathbf{A}$. This suggests that cobalt ion in both $\mathbf{B}$ and $\mathbf{C}$ (Scheme 4) exist in a high-spin divalent oxidation state presumably. The rationale for EPR silent signature of Co(II) ion in a high-spin state $(S=3 / 2)$ is well established already in the literature. ${ }^{58,69-74}$

When an alkyne is added to the in-situ generated species, the EPR signal is re-generated, with characteristic features of an $S=1 / 2$ spin state i.e. $\operatorname{Co}(0)$ (see blue trace in Figure 3 ). The regeneration of the EPR signal due to $\operatorname{Co}(0)$, unambiguously suggest that reductive elimination is the final step of the hydrophosphination catalytic cycle. The EPR spectrum of the final step was simulated by considering $S=1 / 2$ spin state with the spin-Hamiltonian ( $\mathrm{SH}$ ) parameters; $g=$ [2.1622 2.1317 2.002], $A\left({ }^{59} \mathrm{Co}\right)=\left[\begin{array}{lll}136 & 48 & 104\end{array}\right] \mathrm{MHz}$, with isotropic hyperfine coupling, of $a_{\text {iso }}\left({ }^{59} \mathrm{Co}\right)=96 \mathrm{MHz}$; The $\mathrm{SH}$ parameters extracted for $\mathrm{Co}(0)$ regenerated from the final step (A') are slightly different from the SH parameters of extracted for A. This suggests that the regenerated catalyst precursor $\left(\mathbf{A}^{\prime}\right)$ possess slightly modified coordination environment than A. Similar trend has been reported previously when one/two of the organophosphorous ligands in the coordination environment of $\mathrm{Co}(0)$ complexes were replaced by other ligands/solvents. ${ }^{61,65}$ The vacant coordination site formed after the reductive elimination, 
conceivably, occupied by the solvent molecule with the tentative molecular formula of $\left[\mathrm{Co}\left(\mathrm{PMe}_{3}\right)_{3}(\mathrm{~L})\right]($ where $\mathrm{L}=$ solvent $)$.

The spin Hamiltonian parameters extracted for $\mathbf{A}^{\prime}$, reproduce only part of the experimental spectrum, which leave out some of the spectral features in 320-350 mT range (see Figure 3 marked with \# symbol). Origin of these EPR signals is due to an unknown radical impurity. The SH parameters extracted for this from simulation described in ESI (see Figure S8 and its related text). The entire experimental spectral features in the final step were reproduced by considering two different $S=1 / 2$ spin states with the weighted factor of 0.96 (for $\mathbf{A}^{\prime}$ ):0.04 (radical $\mathrm{S}=1 / 2$ ) (blue trace in Figure 3). At this moment, we do not know the origin of radical impurity $(<4 \%)$. Overall, the modified coordination environment for the regenerated catalytic precursor (compared to $\mathbf{A}$ ) is well supported by EPR, NMR and UV-Vis data undisputedly.

Scheme 4. Proposed mechanism.

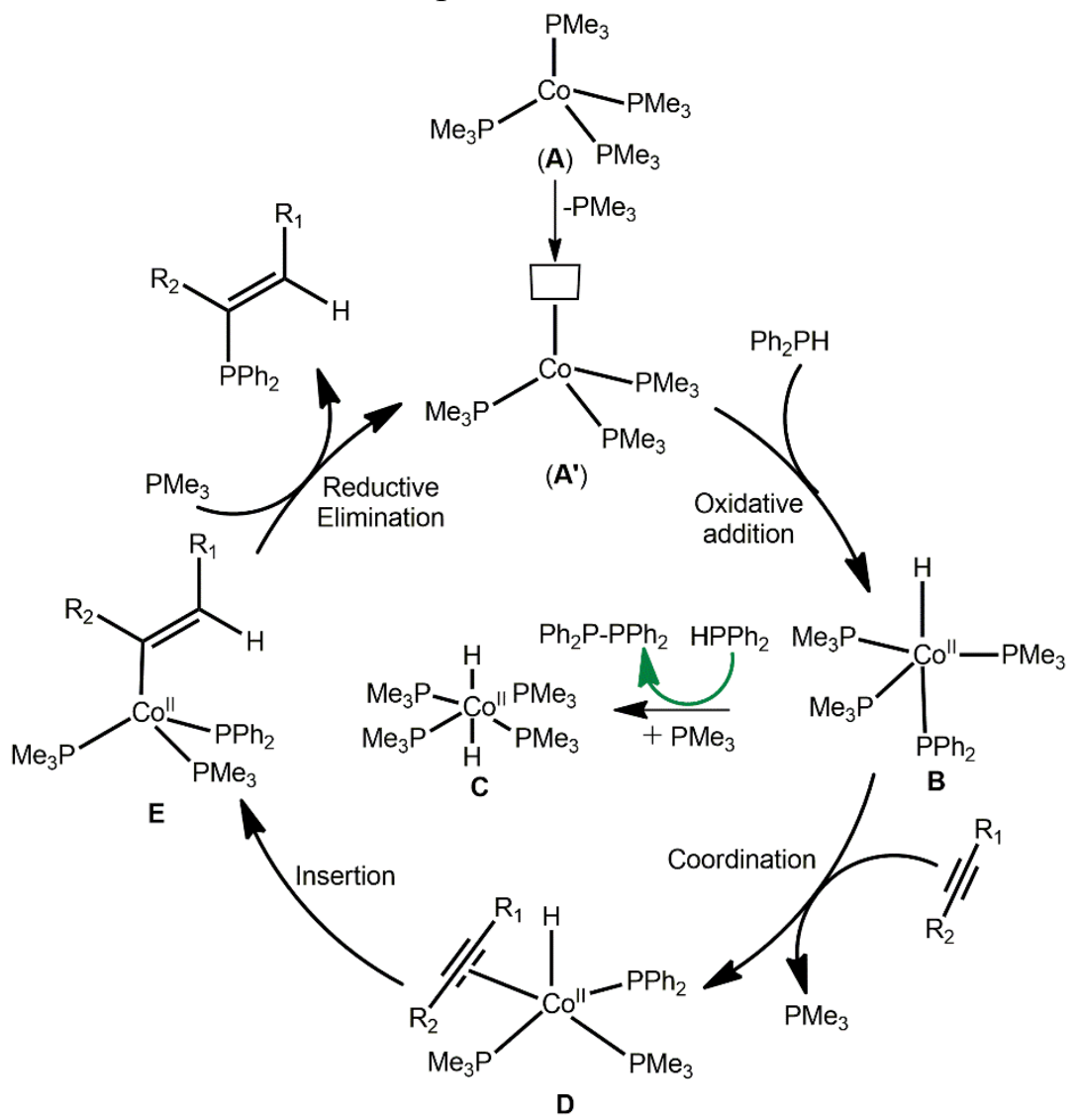


Based on the various spectroscopic observations (NMR, UV-Vis, and EPR (vide supra)), we have proposed the working mechanism as depicted in Scheme 4. Complex A undergo initial ligand dissociation followed by oxidative addition of $\mathrm{P}-\mathrm{H}$ led to the intermediate $\mathbf{B}$. Intermediate $\mathbf{B}$ in the absence of alkynes reacts with $\mathrm{HPPh}_{2}$ and leads to the formation of $\mathbf{C}$ along with the minor coupled product $\left(\mathrm{PPh}_{2}\right)_{2}$. Initial coordination of alkyne to the intermediate B followed by insertion between $\mathrm{Co}-\mathrm{H}$ led to intermediate $\mathbf{D}$, which then proceeded to reductive elimination to produce vinylphosphine and regenerate an active species $\mathbf{A}^{\prime}$ for next catalytic cycle.

\section{Conclusions}

In conclusions, we have shown hydrophosphination of internal and terminal alkynes for the first time using well-defined low valent cobalt(0) complex. The suprafacial addition of P$\mathrm{H}$ bonds across the alkyne in $s y n$-fashion result in regio and stereo selective vinylphoshpine as product. Deuterated labelled experiments undisputedly unveil the origin of regio and stereo selectivity of the isolated products. The reaction is general, applicable for both terminal and internal alkynes with good functional groups tolerance. The detailed NMR, UV-Vis, and EPR spectroscopic methods apparently discloses the presence of species $\mathbf{B}\left(\left[\mathrm{Co}{ }^{\mathrm{II}} \mathrm{H}\left(\mathrm{PMe}_{3}\right)_{3}\left(\mathrm{PPh}_{2}\right)\right]\right)$ in solution upon oxidative addition of $\mathrm{PPh}_{2} \mathrm{H}$ with $\mathbf{A}$. Further in the absence of alkyne, $\mathbf{B}$ reacts with $\mathrm{HPPh}_{2}$ and leads to $\mathbf{C}\left(\left[\mathrm{Co}^{\mathrm{II}}(\mathrm{H})_{2}\left(\mathrm{PMe}_{3}\right)_{4}\right]\right)$. Addition of alkyne substrate into the in-situ generated species $\mathbf{B}$ facilitate reductive elimination which concomitantly regenerate presumably a tricoordinated naked $\operatorname{Co}(0)$ active species. This extensive study allows us to further extend the catalytic system to activate other $\mathrm{X}-\mathrm{H}$ bonds including inert $\mathrm{C}-\mathrm{H}$ bonds, which is currently underway in our laboratory.

\section{Experimental Section: General Remarks.}


All the reactions were carried out under argon atmosphere unless otherwise mentioned. All the alkyne substrate was purchased from commercially available source, except, $(\mathbf{1} \mathbf{j}-\mathbf{1} \mathbf{n})$, (1ab-1ad) is synthesized as per the literature reports. ${ }^{75-77}$ Toluene was purified by means of distillation under dry nitrogen atmosphere over benzophenone /sodium ketyl. $\left[\mathrm{Co}\left(\mathrm{PMe}_{3}\right)_{4}\right]$ was synthesized as per literature procedure. ${ }^{14}$ Chromatography purification was carried out using silica (mess size 60-120) for isolation of the products, additionally thin layer chromatography was performed using Merck TLC silica gel $60 \mathrm{~F}_{254}$ plates. All the NMR $\left({ }^{1} \mathrm{H},{ }^{13} \mathrm{C},{ }^{31} \mathrm{P}\right)$ were recorded on Bruker $400 \mathrm{AVANCE}$ or $500 \mathrm{AVANCE}$ and referenced to $\mathrm{CDCl}_{3}$ or $_{6} \mathrm{C}_{6}$ residual peak. $85 \% \mathrm{H}_{3} \mathrm{PO}_{4}$ was used as external reference for recording ${ }^{31} \mathrm{P}$ NMR. UV-Vis. spectra were recorded on a Shimadzu(UV-NIR-3600) at room temperature. Variable temperature EPR was recorded using a Bruker EMS plus series instrument and the EPR spectra were simulated using easy spin software. ${ }^{60}$

\section{Synthetic procedure:}

\section{General procedure for the hydrophosphination of terminal alkyne}

In an argon filled glove box $16.5 \mathrm{mg}$ of $\left[\mathrm{Co}\left(\mathrm{PMe}_{3}\right)_{4}\right]$ and $0.16 \mathrm{ml}(0.9 \mathrm{mmol})$ of $\mathrm{HPPh}_{2}, 3 \mathrm{ml}$ of toluene was added in an Schlenk tube and the mixture was stirred at room temperature for 10 minutes before adding various alkyne $(0.9 \mathrm{mmol})$ into the reaction mixture. The resultant mixture was heated at $80^{\circ} \mathrm{C}$ for $1-2 \mathrm{hrs}$. Reaction was followed by ${ }^{31} \mathrm{P}$ NMR and consumption of $\mathrm{HPPh}_{2}(-40.5 \mathrm{ppm})$ was monitored. Reaction tube was cooled and $60 \mathrm{mg}$ of $\mathrm{S} 8$ was added into the reaction mixture. This was heated at $80{ }^{\circ} \mathrm{C} 15 \mathrm{~min}$ before the reaction was quenched with water. The mixture was transferred in to a separatory funnel and the compound of interest was extracted in ethyl acetate. The pure product of interest was isolated through column chromatography (pet. ether/ethyl acetate (ratio: 99:1). The Purity of the resultant product were 
confirmed through the ${ }^{1} \mathrm{H}$ and ${ }^{31} \mathrm{P}$ NMR where we had obtained only single peak corresponding to product.

\section{General procedure for the hydrophosphination of internal alkyne}

The same reaction procedure was followed as above, but the reaction mixture was heated at $100^{\circ} \mathrm{C}$ for 12 hours.

\section{Procedure for the NMR follow up}

To follow the intermediates generated in the catalytic cycle, we performed several NMR experiments in a J-Young NMR tube. The general procedure followed described below. $10 \mathrm{mg}$ $(0.0275 \mathrm{mmol})$ of $\left[\mathrm{Co}\left(\mathrm{PMe}_{3}\right)_{4}\right]$ was dissolve in $0.5 \mathrm{ml}$ of $\mathrm{C}_{6} \mathrm{D}_{6}$, in the resulting homogeneous solution $4.7 \mu \mathrm{L}$ of $(0.0275 \mathrm{mmol}) \mathrm{HPPh}_{2}$ was added. Upon addition, the reaction mixture turns into dark brown and the tube was sealed and heated for $15 \mathrm{~min}$. at $70{ }^{\circ} \mathrm{C}$. The resultant mixture was cooled to room temperature and ${ }^{1} \mathrm{H},{ }^{31} \mathrm{P}$ NMR was recorded. The tube was brought inside the glove box and $5 \mathrm{mg}(0.0275 \mathrm{mmol})$ of 4-Bromophenyl acetylene was added into it, sealed and heated at $80{ }^{\circ} \mathrm{C}$ for $30 \mathrm{~min} .{ }^{1} \mathrm{H},{ }^{31} \mathrm{P}$ NMR was recorded for resulting solution. A similar procedure was followed for the isotopic labelled experiments (reaction of A with $\mathrm{DPPh}_{2}$ ) as well, but the NMR was recorded in $\mathrm{C}_{6} \mathrm{H}_{6}$.

\section{Procedure for UV-Vis. follow up}

A similar synthetic method was followed as in NMR follow up, but the reactions were performed in a Schlenk tube fitted with septa in a $1.0 \mathrm{ml}$ toluene solvent. With the help of syringe $0.05 \mathrm{~mL}$ of aliquot was taken from the reaction mixture which is then transferred to a sealed UV-Vis cuvette (containing $3.5 \mathrm{~mL}$ of dry toluene) under inert atmosphere.

\section{Procedure for EPR follow up}


A similar synthetic method was followed as in NMR follow up, but the reactions were performed in a Schlenk tube fitted with septa in a $1.0 \mathrm{ml}$ toluene solvent. With the help of syringe $0.05 \mathrm{~mL}$ of aliquot was taken from the reaction mixture which is then transferred to a sealed EPR tube (containing $0.15 \mathrm{~mL}$ of dry toluene) under inert atmosphere.

\section{ASSOCIATED CONTENT}

Crystallographic data obtained for $\mathbf{2 c}$ and relevant NMR of the isolated products are given in ESI. CCDC number: 1509786

\section{AUTHOR INFORMATION}

\section{Corresponding Author}

eswar@chem.iitb.ac.in ${ }^{\perp *}$

muralidharan.shanmugam@gmail.com*

\section{Present Addresses}

Author Contributions

The manuscript was written through contributions of all authors. All authors have given approval to the final version of the manuscript.

\section{ACKNOWLEDGMENT}

MS acknowledge the funding agencies DST (EMR/2015/000592), IRCC, IIT Bombay, INSA (SP/YSP/119/2015/1264) for the financial assistance. MS acknowledges Manchester Institute of Biotechnology (MIB) and University of Manchester for financial support.

\section{ABBREVIATIONS}

NMR, nuclear magnetic resonance; EPR, electron paramagnetic resonance, UV-vis., ultraviolet visible; ESI, electronic supplementary information.

\section{REFERENCES}


(1) Mimeau, D.; Delacroix, O.; Gaumont, A.-C. Regioselective uncatalysed hydrophosphination of alkenes: a facile route to P-alkylated phosphine derivatives. Chem. Commun. 2003, 2928.

(2) Alonso, F.; Beletskaya, I. P.; Yus, M. Transition-metal-catalyzed addition of heteroatom-hydrogen bonds to alkynes. Chem. Rev. 2004, 104 (6), 3079.

(3) Maas, G. Phosphorus: the Carbon Copy. from Organophosphorus to Phospha-organic Chemistry. K. B. Dillon, F. Mathey, and J. F. Nixon, 1999.

(4) Koshti, V.; Gaikwad, S.; Chikkali, S. H. Contemporary avenues in catalytic PH bond addition reaction: A case study of hydrophosphination. Coord. Chem. Rev. 2014, 265, 52.

(5) Parsons, A. F.; Sharpe, D. J.; Taylor, P. Radical addition reactions of diphenylphosphine sulfide. Synlett 2005, 2981.

(6) Trofimov, B. A.; Malysheva, S. F.; Gusarova, N. K.; Belogorlova, N. A.; Vasilevsky, S. F.; Kobychev, V. B.; Sukhov, B. G.; Ushakov, I. A. Free-radical addition of phosphine sulfides to aryl and hetaryl acetylenes: unprecedented stereoselectivity. Mendeleev Commun 2007, 17 (3), 181.

(7) Glueck, D. S. Metal-catalyzed asymmetric synthesis of P-stereogenic phosphines. Synlett 2007, 2627.

(8) Pringle, P. G.; Smith, M. B. Platinum(0)-catalyzed hydrophosphination of acrylonitrile. $J$ Chem Soc, Chem Commun 1990, 1701.

(9) Yuan, J.; Hu, H.; Cui, C. N-Heterocyclic Carbene-Ytterbium Amide as a Recyclable Homogeneous Precatalyst for Hydrophosphination of Alkenes and Alkynes. Chem. Eur. J. 2016, 22 (16), 5778.

(10) Moglie, Y.; Gonzalez-Soria, M. J.; Martin-Garcia, I.; Radivoy, G.; Alonso, F. Catalystand solvent-free hydrophosphination and multicomponent hydrothiophosphination of alkenes and alkynes. Green Chem. 2016, 18 (18), 4896.

(11) Milligan, J. A.; Busacca, C. A.; Senanayake, C. H.; Wipf, P. Hydrophosphination of bicyclo[1.1.0]butane-1-carbonitriles. Org. Lett. 2016, 18 (17), 4300.

(12) Kamitani, M.; Itazaki, M.; Tamiya, C.; Nakazawa, H. Regioselective double hydrophosphination of terminal arylacetylenes catalyzed by an iron complex. J. Am. Chem. Soc. 2012, 134 (29), 11932.

(13) Itazaki, M.; Katsube, S.; Kamitani, M.; Nakazawa, H. Synthesis of vinylphosphines and unsymmetric diphosphines: iron-catalyzed selective hydrophosphination reaction of alkynes and vinylphosphines with secondary phosphines. Chem. Commun. (Cambridge, U. K.) 2016, 52 (15), 3163.

(14) Hu, H.; Cui, C. Synthesis of Calcium and Ytterbium Complexes Supported by a Tridentate Imino-Amidinate Ligand and Their Application in the Intermolecular Hydrophosphination of Alkenes and Alkynes. Organometallics 2012, 31 (3), 1208.

(15) Bange, C. A.; Waterman, R. Challenges in Catalytic Hydrophosphination. Chem. - Eur. J. 2016, 22 (36), 12598.

(16) Bange, C. A.; Waterman, R. Zirconium-Catalyzed Intermolecular Double Hydrophosphination of Alkynes with a Primary Phosphine. ACS Catal. 2016, 6, 6413.

(17) Chong, C. C.; Kinjo, R. Hydrophosphination of CO2 and Subsequent Formate Transfer in the 1,3,2-Diazaphospholene-Catalyzed N-Formylation of Amines. Angew. Chem., Int. Ed. 2015, 54 (41), 12116.

(18) Di Giuseppe, A.; De Luca, R.; Castarlenas, R.; Perez-Torrente, J. J.; Crucianelli, M.; Oro, L. A. Double hydrophosphination of alkynes promoted by rhodium: the key role of an N-heterocyclic carbene ligand. Chem. Commun. 2016, 52 (32), 5554.

(19) Rivera-Hernandez, A.; Fallon, B. J.; Ventre, S.; Simon, C.; Tremblay, M.-H.; Gontard, G.; Derat, E.; Amatore, M.; Aubert, C.; Petit, M. Regio- and Stereoselective 
Hydrosilylation of Unsymmetrical Alkynes Catalyzed by a Well-Defined, Low-Valent Cobalt Catalyst. Org. Lett. 2016, 18 (17), 4242.

(20) Fallon, B. J.; Derat, E.; Amatore, M.; Aubert, C.; Chemla, F.; Ferreira, F.; Perez-Luna, A.; Petit, M. C2-Alkylation and Alkenylation of Indoles Catalyzed by a Low-Valent Cobalt Complex in the Absence of Reductant. Org. Lett. 2016, 18 (9), 2292.

(21) Sun, J.; Deng, L. Cobalt Complex-Catalyzed Hydrosilylation of Alkenes and Alkynes. ACS Catal. 2016, 6 (1), 290.

(22) Zuo, Z.; Yang, J.; Huang, Z. Cobalt-Catalyzed Alkyne Hydrosilylation and Sequential Vinylsilane Hydroboration with Markovnikov Selectivity. Angew. Chem., Int. Ed. 2016, 55 (36), 10839.

(23) McGough, J. S.; Butler, S. M.; Cade, I. A.; Ingleson, M. J. Highly selective catalytic trans-hydroboration of alkynes mediated by borenium cations and $\mathrm{B}(\mathrm{C} 6 \mathrm{~F} 5) 3$. Chem. Sci. 2016, 7 (5), 3384.

(24) Fallon, B. J.; Garsi, J.-B.; Derat, E.; Amatore, M.; Aubert, C.; Petit, M. Synthesis of 1,2-Dihydropyridines Catalyzed by Well-Defined Low-Valent Cobalt Complexes: CH Activation Made Simple. ACS Catal. 2015, 5 (12), 7493.

(25) Ishikawa, T.; Sonehara, T.; Minakawa, M.; Kawatsura, M. Copper-Catalyzed Intermolecular Hydroamination of Internal Alkynes with Anilines and Amines. Org. Lett. 2016, 18 (6), 1422.

(26) Yang, H.; Gabbai, F. P. Activation of a Hydroamination Gold Catalyst by Oxidation of a Redox-Noninnocent Chlorostibine Z-Ligand. J. Am. Chem. Soc. 2015, 137 (41), 13425.

(27) Jang, W. J.; Lee, W. L.; Moon, J. H.; Lee, J. Y.; Yun, J. Copper-Catalyzed transHydroboration of Terminal Aryl Alkynes: Stereodivergent Synthesis of Alkenylboron Compounds. Org. Lett. 2016, 18 (6), 1390.

(28) Sundararaju, B.; Fuerstner, A. A trans-Selective Hydroboration of Internal Alkynes. Angew. Chem., Int. Ed. 2013, 52 (52), 14050.

(29) Obligacion, J. V.; Neely, J. M.; Yazdani, A. N.; Pappas, I.; Chirik, P. J. Cobalt catalyzed Z-selective hydroboration of terminal alkynes and elucidation of the origin of selectivity. J. Am. Chem. Soc. 2015, 137 (18), 5855.

(30) Huang, L.; Arndt, M.; Goossen, K.; Heydt, H.; Goossen, L. J. Late Transition MetalCatalyzed Hydroamination and Hydroamidation. Chem. Rev. 2015, 115 (7), 2596.

(31) Takachi, M.; Chatani, N. Nickel-Catalyzed Hydrosilylation/Cyclization of DifluoroSubstituted 1,6-Enynes. Org. Lett. 2010, 12 (22), 5132.

(32) Shi, S.-L.; Buchwald Stephen, L. Copper-catalysed selective hydroamination reactions of alkynes. Nat. Chem. 2015, 7 (1), 38.

(33) Maity, S.; Kancherla, R.; Dhawa, U.; Hoque, E.; Pimparkar, S.; Maiti, D. Switch to Allylic Selectivity in Cobalt-Catalyzed Dehydrogenative Heck Reactions with Unbiased Aliphatic Olefins. ACS Catal. 2016, 6, 5493.

(34) Hong, S.; Marks, T. J. Organolanthanide-Catalyzed Hydroamination. Acc. Chem. Res. 2004, 37 (9), 673.

(35) Schlepphorst, C.; Wiesenfeldt, M. P.; Glorius, F. Enantioselective Hydrogenation of Imidazo[1,2-a]pyridines. Chem. - Eur. J. 2018, 24 (2), 356.

(36) Palmer, W. N.; Diao, T.; Pappas, I.; Chirik, P. J. High-Activity Cobalt Catalysts for Alkene Hydroboration with Electronically Responsive Terpyridine and $\alpha$-Diimine Ligands. ACS Catal. 2015, 5 (2), 622.

(37) Wang, X.; Nakajima, M.; Serrano, E.; Martin, R. Alkyl Bromides as Mild Hydride Sources in Ni-Catalyzed Hydroamidation of Alkynes with Isocyanates. J. Am. Chem. Soc. 2016, 138 (48), 15531. 
(38) Musa, S.; Ghosh, A.; Vaccaro, L.; Ackermann, L.; Gelman, D. Efficient E-Selective Transfer Semihydrogenation of Alkynes by Means of Ligand-Metal Cooperating Ruthenium Catalyst. Adv. Synth. Catal. 2015, 357 (10), 2351.

(39) Thomas, S. P.; Aggarwal, V. K. Asymmetric hydroboration of 1,1-disubstituted alkenes. Angew. Chem., Int. Ed. 2009, 48 (11), 1896.

(40) Guthertz, A.; Leutzsch, M.; Wolf, L. M.; Gupta, P.; Rummelt, S. M.; Goddard, R.; Fares, C.; Thiel, W.; Fuerstner, A. Half-Sandwich Ruthenium Carbene Complexes Link trans-Hydrogenation and gem-Hydrogenation of Internal Alkynes. J. Am. Chem. Soc. 2018, 140 (8), 3156.

(41) Jerome, F.; Monnier, F.; Lawicka, H.; Derien, S.; Dixneuf, P. H. Ruthenium catalyzed regioselective hydrophosphination of propargyl alcohols. Chem. Commun. (Cambridge, U. K.) 2003, 696.

(42) Bruneau, C.; Dixneuf, P. H. Metal Vinylidenes in Catalysis. Acc. Chem. Res. 1999, 32 (4), 311.

(43) Kazankova, M. A.; Efimova, I. V.; Kochetkov, A. N.; Afanas'ev, V. V.; Beletskaya, I. P. Synthesis of vinylphosphines by hydrophosphination of alkynes in the presence of transition metal complexes. Russ. J. Org. Chem. 2002, 38 (10), 1465.

(44) Motta, A.; Fragala, I. L.; Marks, T. J. Energetics and Mechanism of OrganolanthanideMediated Phosphinoalkene Hydrophosphination/Cyclization. A Density Functional Theory Analysis. Organometallics 2005, 24 (21), 4995.

(45) Takaki, K.; Koshoji, G.; Komeyama, K.; Takeda, M.; Shishido, T.; Kitani, A.; Takehira, K. Intermolecular Hydrophosphination of Alkynes and Related Carbon-Carbon Multiple Bonds Catalyzed by Organoytterbiums. J. Org. Chem. 2003, 68 (17), 6554.

(46) Liu, B.; Roisnel, T.; Carpentier, J.-F.; Sarazin, Y. Heteroleptic Alkyl and Amide Iminoanilide Alkaline Earth and Divalent Rare Earth Complexes for the Catalysis of Hydrophosphination and (Cyclo)Hydroamination Reactions. Chem. - Eur. J. 2013, 19 (40), 13445.

(47) Wang, F.; Wang, S.; Zhu, X.; Zhou, S.; Miao, H.; Gu, X.; Wei, Y.; Yuan, Q. Novel Lanthanide Amides Incorporating Neutral Pyrrole Ligand in a Constrained Geometry Architecture: Synthesis, Characterization, Reaction, and Catalytic Activity. Organometallics 2013, 32 (14), 3920.

(48) Yuan, Q.; Zhou, S.; Zhu, X.; Wei, Y.; Wang, S.; Mu, X.; Yao, F.; Zhang, G.; Chen, Z. Heterometallic rare-earth metal complexes with imino-functionalized 8hydroxyquinolyl ligands: synthesis, characterization and catalytic activity towards hydrophosphinylation of trans- $\beta$-nitroalkene. New J. Chem. 2015, 39 (10), 7626.

(49) Rosenberg, L. Mechanisms of Metal-Catalyzed Hydrophosphination of Alkenes and Alkynes. ACS Catal. 2013, 3 (12), 2845.

(50) Kazankova, M. A.; Shulyupin, M. O.; Beletskaya, I. P. Catalytic hydrophosphination of alkenyl alkyl ethers. Synlett 2003, 2155.

(51) Shulyupin, M. O.; Kazankova, M. A.; Beletskaya, I. P. Catalytic Hydrophosphination of Styrenes. Org. Lett. 2002, 4 (5), 761.

(52) Kazankova, M. A.; Shulyupin, M. O.; Borisenko, A. A.; Beletskaya, I. P. Synthesis of alkyl(diphenyl)phosphines by hydrophosphination of vinylarenes catalyzed by transition metal complexes. Russ. J. Org. Chem. 2002, 38 (10), 1479.

(53) Ohmiya, H.; Yorimitsu, H.; Oshima, K. Cobalt-catalyzed syn hydrophosphination of alkynes. Angew. Chem., Int. Ed. 2005, 44 (16), 2368.

(54) Radkowski, K.; Sundararaju, B.; Fuerstner, A. A Functional-Group-Tolerant Catalytic trans Hydrogenation of Alkynes. Angew. Chem., Int. Ed. 2013, 52 (1), 355. 
(55) Takaki, K.; Komeyama, K.; Takehira, K. Synthesis of lanthanide(II)-imine complexes and their use in carbon-carbon and carbon-nitrogen unsaturated bond transformation. Tetrahedron 2003, 59 (52), 10381.

(56) Levison, J. J.; Robinson, S. D. Hydrido(triaryl phosphite) complexes of cobalt, rhodium, and iridium. Chem Commun 1968, 1405.

(57) Geer, A. M.; Serrano, A. L.; de Bruin, B.; Ciriano, M. A.; Tejel, C. Terminal Phosphanido Rhodium Complexes Mediating Catalytic P-P and P-C Bond Formation. Angew. Chem., Int. Ed. 2015, 54 (2), 472.

(58) Banci, L.; Bencini, A.; Benelli, C.; Gatteschi, D.; Zanchini, C. Spectral-structural correlations in high-spin cobalt(II) complexes. Struct. Bonding (Berlin) 1982, 52, 37.

(59) Morassi, R.; Bertini, I.; Sacconi, L. Five-coordination iron(II), cobalt(II), and nickel(II) complexes. Coord. Chem. Rev. 1973, 11 (4), 343.

(60) Stoll, S.; Schweiger, A. EasySpin, a comprehensive software package for spectral simulation and analysis in EPR. J. Magn. Reson. 2006, 178 (1), 42.

(61) Vinogradov, M. G.; Tuzikov, A. B.; Nikishin, G. I.; Shelimov, B. N.; Kazansky, V. B. Unusual type of catalysis by paramagnetic cobalt( 0$)$ complexes. Isolation of catalytically active 17-electron intermediate, $\left(\mathrm{Ph}_{3} \mathrm{P}\right)_{2} \mathrm{Co}\left(\mathrm{CH}_{2}=\mathrm{CHCH}_{2} \mathrm{CH}_{2} \mathrm{CHO}\right)$, in the 4-pentenal intramolecular hydroacylation. J. Organomet. Chem. 1988, 348 (1), 123.

(62) Klein, H. F. Tetrakis(trimethylphosphane)cobalt(O). Preparation and reactions. Angew. Chem., Int. Ed. Engl. 1971, 10 (5), 343.

(63) Larin, G. M.; Saraev, V. V.; Shmidt, F. K.; Lipovich, V. G. EPR study of complexes of cobalt $(0)$ with organophosphorus ligands in catalytic systems. Izv. Akad. Nauk SSSR, Ser. Khim. 1974, (4), 904.

(64) Saraev, V. V.; Shmidt, F. K.; Larin, G. M.; Lipovich, V. G. EPR study of cobalt(0) complexes in catalytic systems. Izv. Akad. Nauk SSSR, Ser. Khim. 1974, (1), 211.

(65) Klein, H. F. Trimethylphosphine complexes of nickel, cobalt, and iron - model compounds for homogeneous catalysis. Angew. Chem. Int. Ed., 1980, 92 (5), 362.

(66) Agnes, G.; Bassi, I. W.; Benedicenti, C.; Intrito, R.; Calcaterra, M.; Santini, C. Preparation and $\mathrm{X}$-ray crystal structure of racemic bis(ethylfumarate)bis(acetonitrile)cobalt(0). J. Organomet. Chem. 1977, 129 (3), 401.

(67) Agnes, G.; Bart, J. C. J.; Santini, C.; Woode, K. A. Trialkyl phosphite complexes of cobalt. J. Am. Chem. Soc. 1982, 104 (19), 5254.

(68) Chatt, J.; Hart, F. A.; Rosevear, D. T. Reaction of metals with ophenylenebis(diethylphosphine). J. Chem. Soc. 1961, 5504.

(69) Novikov, V. V.; Pavlov, A. A.; Belov, A. S.; Vologzhanina, A. V.; Savitsky, A.; Voloshin, Y. Z. Transition Ion Strikes Back: Large Magnetic Susceptibility Anisotropy in Cobalt(II) Clathrochelates. J. Phys. Chem. Lett. 2014, 5 (21), 3799.

(70) Sottini, S.; Poneti, G.; Ciattini, S.; Levesanos, N.; Ferentinos, E.; Krzystek, J.; Sorace, L.; Kyritsis, P. Magnetic Anisotropy of Tetrahedral CoII Single-Ion Magnets: SolidState Effects. Inorg. Chem. 2016, 55 (19), 9537.

(71) Novikov, V. V.; Pavlov, A. A.; Nelyubina, Y. V.; Boulon, M.-E.; Varzatskii, O. A.; Voloshin, Y. Z.; Winpenny, R. E. P. A Trigonal Prismatic Mononuclear Cobalt(II) Complex Showing Single-Molecule Magnet Behavior. J. Am. Chem. Soc. 2015, 137 (31), 9792.

(72) Pilbrow, J. R. Transition Ion Electron Paramagnetic Resonance,Clarendon, Oxford,. 1990.

(73) Vaidya, S.; Shukla, P.; Tripathi, S.; Rivière, E.; Mallah, T.; Rajaraman, G.; Shanmugam, M. Substituted versus Naked Thiourea Ligand Containing Pseudotetrahedral Cobalt (II) Complexes: A Comparative Study on Its Magnetization Relaxation Dynamics Phenomenon. Inorg. Chem. 2018, 57 (6), 3371. 
(74) Vaidya, S.; Singh, S. K.; Shukla, P.; Ansari, K.; Rajaraman, G.; Shanmugam, M. Role of Halide Ions in the Nature of the Magnetic Anisotropy in Tetrahedral CoII Complexes. Chem.-Eur. J., 2017, 23 (40), 9546.

(75) Rodriguez, M. R.; Beltran, A.; Mudarra, A. L.; Alvarez, E.; Maseras, F.; Diaz-Requejo, M. M.; Perez, P. J. Catalytic Nitrene Transfer To Alkynes: A Novel and Versatile Route for the Synthesis of Sulfinamides and Isothiazoles. Angew. Chem., Int. Ed. 2017, 56 (42), 12842.

(76) Singh, S.; Goo, J.-I.; Noh, H.; Lee, S. J.; Kim, M. W.; Park, H.; Jalani, H. B.; Lee, K.; Kim, C.; Kim, W.-K.et al. Discovery of a novel series of N-hydroxypyridone derivatives protecting astrocytes against hydrogen peroxide-induced toxicity via improved mitochondrial functionality. Bioorg. Med. Chem. 2017, 25 (4), 1394.

(77) Li, R.-H.; Ding, Z.-C.; Li, C.-Y.; Chen, J.-J.; Zhou, Y.-B.; An, X.-M.; Ding, Y.-J.; Zhan, Z.-P. Thiophene-Alkyne-Based CMPs as Highly Selective Regulators for Oxidative Heck Reaction. Org. Lett. 2017, 19 (17), 4432. 


\section{Table of Content}

A well-defined cobalt $(0)$ catalyst $\left(\left[\mathrm{Co}\left(\mathrm{PPh}_{3}\right)_{4}\right] ; \mathbf{A}\right)$ promotes hydrophosphination reaction of both terminal and internal alkynes with excellent stereo and regio-selectivity $(E$ isomer). In addition, we report, through detailed spectroscopic (NMR, UV-Vis and EPR) analyses and isotopic labelling methods various intermediates involved in the catalytic cycle identified.

\section{Substrate}

Highly regio and stereoselective

Well characterized intermediate by NMR, EPR, UV-vis.

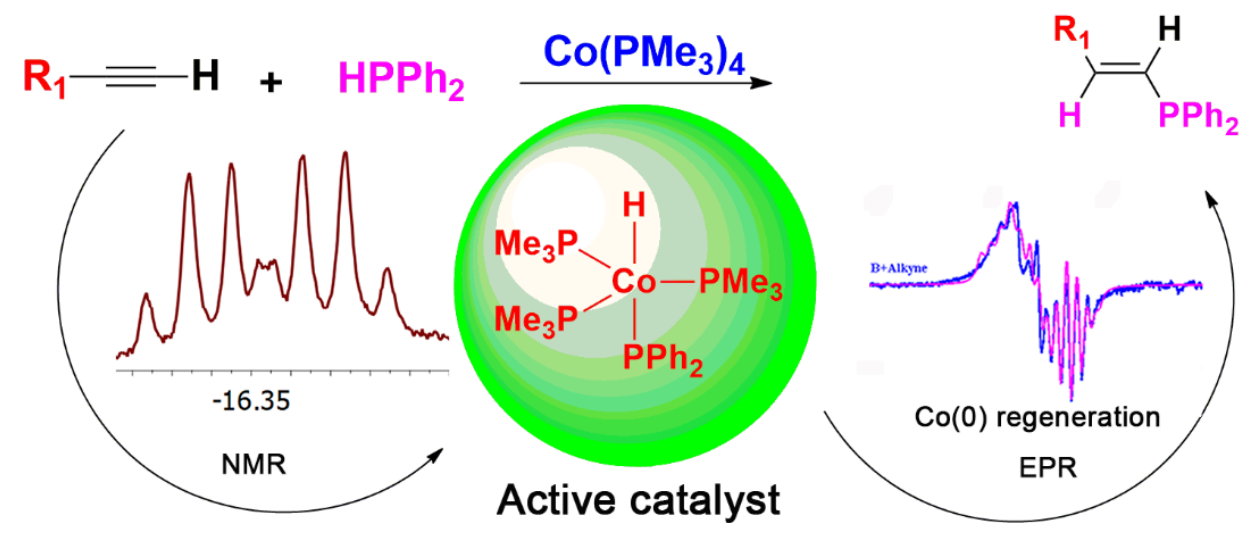

